\title{
AÇÃO PEDAGÓGICA DO PROFESSOR NA APRENDIZAGEM DA LÍNGUA INGLESA
}

\author{
Teacher's pedagogical action in english language learning
}

\section{Antonio Filipe Maciel Szezecinski ${ }^{1}$ \\ Célia de Fátima Rosa da Veiga ${ }^{2}$ \\ Maria Luísa Spicer-Escalante ${ }^{3}$}

RESUMO: Os objetivos deste estudo é evidenciar quais as estratégias utilizadas por alunos adultos na aprendizagem da Língua Inglesa e como elas ocorrem, dentro do contexto de uma sala de aula de uma escola de idiomas. O cenário de sala de aula observado correspondeu à realidade educacional de duas turmas de nivelamento básico em Inglês. O estudo de caso, com abordagem qualitativa, foi dividido em dois momentos: observações iniciais e entrevistas realizadas com alunos adultos das turmas observadas. Constatou-se que o aluno, além do auxílio do professor dentro da sala de aula, usou aplicativos como o Google Tradutor. Também foi possível verificar que por mais que ao aluno seja proporcionado materiais extras ou apoio docente, a aquisição e aprendizagem da Língua Inglesa somente é possível quando ele assume a posição de principal agente no seu processo de aprendizagem.

Palavras-chaves: Aprendizagem da Língua Inglesa. Estratégias de Aprendizagem. Aprendizagem de Adultos em Língua Inglesa. Professor.

ABSTRACT: The objectives of this study are to highlight which strategies are used by adult students in learning the English language and how they occur, within the context of a language school classroom. The classroom scenario observed corresponded to the educational reality of two basic level English classes. The case study, with a qualitative approach, was divided into two moments: initial observations and interviews with adult students from the observed classes. It was found that the student, in addition to the help of the teacher within the classroom, used applications such as Google Translate. It was also

\footnotetext{
1 Mestre e Doutorando em Educação pela Universidade La Salle - Canoas-RS. antonio.szezecinski@gmail.com

${ }^{2}$ Mestre e Doutoranda em Educação pela Universidade La Salle - Canoas-RS. celiavei16@gmail.com

${ }^{3}$ Doctora en Estudios lingüísticos. Docente na Utah State University - Estados Unidos da América do Norte, EUA.. E-mail: maria.spicer@usu.edu
} 
possible to verify that, although the student is provided with extra materials or teaching support, the acquisition and learning of the English language is only possible when he assumes the position of main agent in his learning process.

Keywords: English Language Learning. Learning Strategies. English Language Learning for Adults. Teacher.

\section{INTRODUÇÃO}

A necessidade de destacar-se em meio a uma sociedade, na qual a demanda aponta a um imediatismo, a um supérfluo ultravalorizado por meio de mídias sociais de diferentes naturezas e essências, conduz muitas vezes à falta de objetivos ao ser humano. Concomitantemente, vive-se em um mundo onde, cada vez mais, as barreiras culturais, estão sendo derrubadas.

Em conjunto a este panorama delineado pelas nascentes tecnologias de última geração e um ritmo quase vertiginoso, há o acesso a diversas fontes de informação tomando proporções que, até há alguns anos, jamais haveria de se cogitar. Com apenas um clique do mouse há, instantaneamente, uma obtenção virtual de infinitas possibilidades temáticas que confluem umas após as outras a esta interligada rede de computadores conhecida como $W$ orld Wide Web. É neste sentido que, nesta era virtual, o ensejo em aprender uma Língua Estrangeira torna-se, uma necessidade. A sua aprendizagem torna-se recurso pelo qual o cidadão deste mundo globalizado tenta se diferenciar dos demais no competitivo mercado de trabalho; mercado este tomado fortemente pela influência de uma língua, que hoje tem proporções globais jamais presenciadas na História até então - a Língua Inglesa.

Em um adendo, uma pesquisa elaborada pelo Instituto de Pesquisa Data Popular para o British Council chamada "Demandas de Aprendizagem de Inglês no Brasil" (2013), organização internacional do Reino Unido para relações culturais e oportunidades educacionais, mostra que, no Brasil, pelo menos 5,1\% da população de 16 anos ou mais possui algum conhecimento do idioma. No entanto, diferenças entre as gerações mais jovens, de 18 a 24 anos, o índice deste porcentual dobra. Em contrapartida desta realidade, chocamse quando questionados sobre a falta de um Ensino Básico de qualidade somada ao baixo 
acesso a cursos privados de Inglês, resultando ao mercado de trabalho dificuldades em encontrar profissionais que tenham proficiência ou fluência na Língua Inglesa.

Neste sentido, compreender, no âmbito da sala de aula, as condições de produção nas quais uma frase pode ser dita, ou seja, em quais situações de interlocução a frase pode ou deve ser usada para a construção dos sentidos, é necessário para a aprendizagem entre sujeitos adultos. A velha fórmula da elicitação repetitiva e mecânica de frases feitas, ou a tradução termo a termo de palavras isoladas, acaba por se tornar uma tentativa vã de se aprender uma Língua Estrangeira. Isso acaba por nos levar a questionar acerca dos procedimentos pelos quais ocorre efetivamente a aprendizagem da Língua Inglesa.

\section{ESTRATÉGIAS DE APRENDIZAGEM EM LÍNGUA INGLESA}

Quando atravessa os pensamentos de determinado indivíduo o vocábulo "estratégia", pensa-se, primeiramente, como um sinônimo para a ideia de encontrar maneiras diferentes para se atingir algum objetivo. Isso não deixa de ser concreto, mas, ao mesmo tempo, soaria um tanto redundante em deter-se somente a uma significação simples. Poderse-ia, neste sentido, pensar a respeito da finalidade de uma estratégia quando determinado sujeito, posto em uma situação em que se confronta com algo, e o tenha que resolver, adota uma forma de cumpri-la de uma maneira concreta.

Dentro do campo da aprendizagem, Perraudeau (2009) destaca que, em muitas ocasiões, a estratégia em si simboliza uma "coordenação de procedimentos, escolhidos em um painel de possibilidades, em razão de uma suposta eficiência e em função de uma dada finalidade" (p. 7). O uso de uma estratégia em meio à aprendizagem suporia uma coexistência de variadas condições, das quais o mesmo autor elenca a lucidez do sujeito sobre a tarefa a ser realizada, a compreensão percebida por este no objetivo apresentado, sua capacidade em movimentar um agrupamento de procedimentos e a efetuação da escolha entre eles.

Outros autores tem enfatizado a importância a importância do design dado pelos professores ao ensino ministrado ao ensinar uma segunda língua, assim como a relevância e necessidade da conexão que deve ser dada entre as tarefas e a vida real dos estudantes, ou seja, o contexto no qual o estudante está envolvido. (ELLIS et al 2019; SHRUM; GLISAN, 2016; SPICER-ESCALANTE, 2019; VANPATTEN, 2017)

Assim, para qualquer atividade que demande determinado esforço, em que o indivíduo tenha de utilizar seus conhecimentos prévios perante ela, este deve usar capacidades precisas e que possam agir perante os materiais a sua disposição para a execução da tarefa, para, assim, 
extrair sua ideia principal. Para cada atividade apresentada dentro do ambiente da sala de aula, existe esta ou aquela estratégia que haverá de ser escolhida para sua aquisição, dependendo da preferência de cada indivíduo e do contexto ao qual está exposto.

Atinge-se, portanto, um objetivo de determinada tarefa, quando se desenvolve uma estratégia particular que, apoiada em capacidades já dominadas, possibilita a construção de um conceito novo, criando-se, assim, uma nova capacidade. De tal maneira, a partir de uma competência dominada e de capacidades já delineadas, desenvolver-se-á uma nova estratégia de acordo com sua complexidade, levando à construção de novas capacidades, possibilitando a fecundação de novas estratégias.

Quando se volta ao uso de estratégias de aprendizagem no contexto da Aquisição da Segunda Língua, percebe-se que seu uso não se difere tanto do uso geral em sala de aula. Oxford (1990), Shrum e Glisan (2016) frisam que tais estratégias são importantes para o aprendizado linguístico, pois são ferramentas para um envolvimento ativo de sua aprendizagem, tornando-se essencial para o desenvolvimento das competências comunicativas.

De acordo com Oxford (2003), estratégias de aprendizagem são percebidas como comportamentos específicos que alunos utilizam para aprimorar sua aprendizagem em uma Língua Estrangeira. A autora também lembra que uma estratégia dada não é nem boa tampouco ruim, é simplesmente neutra até que o contexto no qual ela será aplicada seja considerado. Para que uma estratégia possa alcançar resultados positivos, três condições devem, em sua essência, ser consideradas: quando a estratégia se relaciona bem na tarefa de Língua Estrangeira no momento; quando a estratégia se encaixa às preferências de estilo de aprendizagem do aluno; e quando a estratégia é empregada efetivamente pelo aluno e relaciona-se com outras estratégias relevantes. Estudos com perspectivas similares as de Oxford (2003) têm sido realizadas por Ellis et al (2019), Lee e VanPatten (2003), Lightbown e Spada (2013), VanPatten (2017) entre outros.

Quando estas estratégias alcançam estas condições, elas fazem com que o processo de aprendizagem seja mais efetivo, mais rápido e mais fácil ao aluno, ocasionando, também, que ele se torne um aprendiz mais independente. Quando os alunos não são incentivados pelo professor a usar seus próprios recursos e métodos de estudo do objeto diante deles, tendem a empregar estratégias nas quais refletem seus estilos de aprendizagem mais básicos. As estratégias de aprendizagem são intencionalmente utilizadas e conscientemente controladas pelo aluno, o que se torna um movimento ciente em torno de determinado objetivo linguístico a ser alcançado sob este prisma. 
Dentro da aprendizagem em Língua Estrangeira, o uso de estratégias de aprendizagem é fortemente relacionado ao alcance e à proficiência da língua. Alunos que frequentemente empregam estratégias de aprendizagem em sua aquisição da Língua Estrangeira desfrutam de um alto nível de autoeficácia. Dessa maneira, percebe-se que estratégias de linguagem apropriadas são aquelas que auxiliam no desenvolvimento de bons aprendizes de uma Língua Estrangeira. Ao mesmo tempo, estratégias de aprendizagem inapropriadas são as que auxiliam no entendimento das falhas frequentes de aprendizes de baixa produtividade.

A partir do momento em que o aluno em questão assume responsabilidades de sua própria aprendizagem, reforça sua autonomia como aprendiz. Como Oxford e Nyikos (1989) complementam, estes fatores tornam-se importantes em virtude de estes aprendizes necessitarem seguir firmes em sua aprendizagem, mesmo quando não estão situados dentro do universo da sala de aula. As autoras também comentam que estudos demonstram que as estratégias de aprendizagem voltadas à língua estrangeira ajudam seus respectivos aprendizes a assimilar novas informações as suas já preexistentes estruturas mentais, criando, assim, um esquema complexo e rico. $\mathrm{Na}$ medida em que estes alunos vão avançando em seus estudos de língua estrangeira, eles acabam por desenvolver seus próprios entendimentos e modelos dentro de sua aquisição na língua-alvo. Diferentemente das demais características que um aluno pode apresentar em seu processo de aprendizagem, tais como aptidão e estilo cognitivo geral, as estratégias de aprendizagem que utiliza são facilmente receptivas ao ensino.

\section{O CAMINHO DA PESQUISA}

Para a condução desta pesquisa de natureza qualitativa, utilizou-se como procedimento técnico um estudo de caso desenvolvido em um ambiente escolar que compreende uma determinada escola de idiomas, a qual não haverá de ser nomeada. Ferramentas de roteiros de observação e entrevistas foram empregadas, seguidas por análises textuais discursivas como forma de melhor analisar o corpus formado pelos roteiros de observação e as entrevistas realizadas.

Foram observadas duas turmas do programa de nivelamento básico. As turmas serão aqui nomeadas "A" e "B". Tal medida é adotada na pesquisa em virtude dos termos de sigilo entregues em forma de carta de apresentação à direção da escola, visando o sigilo compromissado previamente.

Após as observações realizadas no primeiro semestre de 2017, 15 alunos foram convidados a participar da entrevista traçada pela pesquisa. O critério de escolha se deu pelo fato 
de estar na faixa etária característica de um adulto e ter frequentado todas as aulas observadas anteriormente. Um total de 11 alunos participou da entrevista, os demais não tiveram disponibilidade.

\section{Professor e Alunos no Contexto da Sala de Aula de Língua Inglesa}

Cada aluno observado neste primeiro momento possuía sua própria motivação para o aprendizado da Língua Inglesa: seja por motivos pessoais que englobavam viagens pelo mundo, ou por motivos profissionais, devido a importante representação que a língua tinha no universo ao qual este aluno estava situado, isso servia como uma motivação própria e única em seu processo de aquisição e aprendizagem na Língua Inglesa.

As observações feitas junto a estas turmas proporcionaram reflexões a serem consideradas na composição e escrita da pesquisa. Por mais que ambas as turmas estivessem situadas pedagógica e linguisticamente no nivelamento básico de Inglês, pôde-se perceber, em muitos aspectos, pontos que os distanciavam e pontos que os aproximavam. Vale lembrar, também, que as turmas observadas estavam um semestre de diferença uma da outra.

Os alunos, em geral, apoiavam-se muito durante as explicações dos professores quanto ao recurso da escrita: palavras novas, diferenças de uso de expressões, significações atribuídas a vocábulos aprendidos, eram todos transcritos em cadernos ou nas bordas das páginas dos Student's Books. Como serão observados nas respostas coletadas das entrevistas conduzidas junto a estes alunos, muitos deles utilizavam-se desta estratégia como forma adotada por eles quando reservavam um momento aos estudos individuais.

Outro ponto a levantar neste contexto é a resistência ao uso da Língua Inglesa em sala de aula quando da comunicação oral. Por mais que na turma "B" o incentivo docente ao uso da língua era presente nos momentos de aprendizagem, muitos dos alunos recusavam-se ou evitavam o uso de palavras ainda não dominadas por eles. Mesmo com a presença de elementos na sala de aula incentivadores ao uso prático e oral da língua, e tendo também o professor os lembrando sistematicamente de tal prática, os alunos ainda eram limitados pelas barreiras linguísticas erguidas entre eles. Já no caso da turma "A", por ter tido naquele semestre o seu primeiro contato em espaço áulico com a Língua Inglesa, a resistência se mantinha, bem como a insegurança e o receio de pronunciar as palavras ali aprendidas. $\mathrm{O}$ primeiro passo a ser dado é possibilitar o desenvolvimento da autoconfiança. Essa construção somente será possível com a cooperação de professor e aluno neste contexto, 
uma vez que a confiança se revela como "[...] chave para o aprendizado eficaz" (DEAQUINO, 2007, p. 66).

Os alunos de ambas as turmas possuíam um bom relacionamento com seu professor. A reciprocidade demarcada nesta relação proporcionou para os alunos momentos que possibilitaram uma compreensão das atividades introduzidas em sala de aula. Por mais, no entanto, que os alunos da turma "A" tivessem uma relação boa com o seu professor, muitos momentos em sua aprendizagem acabaram sendo afetados, uma vez que se detinham em devaneios aleatórios durante a execução das tarefas, afastando-se do principal objetivo almejado pelo professor.

Outro ponto que chamou a atenção durante as observações foi a postura que alguns alunos haviam adotado no desenvolvimento das aulas. Os alunos provenientes da turma " $\mathrm{A}$ ", por exemplo, em determinadas ocasiões, centravam suas expectativas de aprendizado linguístico no seu professor. Os alunos da turma "B", entretanto, já demonstravam um comportamento diferente, com alguns adotando uma postura mais ativa e independente em seu aprendizado, apesar de outros terem demonstrado uma certa passividade para aprender, deixando-se ser conduzido, às vezes, pelo erro, e esperando pela correção do professor.

Lemov (2011) denota a importância da participação ativa do aluno em seu processo de aprendizagem. Ele acredita que este envolvimento maior dos alunos na aprendizagem "[...] permite que todos trabalhem na sala e sinaliza para os alunos não apenas que eles podem ser chamados a participar a qualquer momento - e, portanto, que devem se envolver no trabalho da aula -, mas também que você quer saber o que eles têm a dizer" (p. 131), estimulando um engajamento positivo seu aos conteúdos administrados por ele em sala de aula.

Tendo em vista as observações realizadas em sala de aula feitas no primeiro semestre do ano letivo, tinha-se já uma ideia de como este aluno reagia a determinadas atividades no espaço áulico ou quanto a forma como respondiam as atividades conduzidas pelo professor.

Desde fatores como traduções em demasia da professora, bem como o não incentivo do uso da língua, revelaram-se cruciais a estes alunos. Em muitas ocasiões os alunos eram apresentados ao contexto linguístico de maneira minuciosa pela professora. $\mathrm{Na}$ maioria das vezes, porém, estes alunos perdiam a atenção, ou mesmo trocavam o foco desta atenção da professora pelo aparelho celular. Ballman, Liskin-Gasparro \& Mandell (2001) destacam que o que leva um professor a não adotar um método comunicativo em sala de aula, é o receio de uma inexatidão na pronúncia do aluno, desejando uma precisão na pronúncia, uma cobrança feita entre professor e corpo discente. 
Outro ponto levantado por Ballman, Liskin-Gasparro \& Mandell (2001), Lee, VanPatten (2003) e Ellis et al (2019), quando pensado a respeito do papel de uma Língua Estrangeira na vida do aluno, é que é mais do que uma simples matéria para que o aluno memorize suas regras e usos, mas sim uma língua única que milhões de pessoas utilizam em uma "base diária de trabalho, brincadeiras, assistir televisão, sair com os amigos, e muito mais” (p. 9). Nesse aspecto, os alunos acabam por construir bases sólidas de experiências compartilhadas, fazendo atividades e ações juntos, dividindo suas expectativas e anseios perante a aprendizagem, e principalmente ao uso prático e oral da língua estudada.

O que acontecia com uma frequência maior nas aulas da turma do Básico "A", por exemplo, era que aos alunos era proposta uma determinada tarefa com certo fim pedagógico. Muitas vezes os alunos permitiam-se ser conduzidos pela professora na obtenção das respostas, conforme pode ser analisado na aula em que eles deveriam preencher uma atividade de cruzadinha, que visava o estudo das diferentes nacionalidades em Língua Inglesa. Além de os alunos terem perdido o foco da atividade, não conseguiram entender qual era o propósito da mesma.

Também, o que veio a chamar a atenção no decorrer das respostas que foram obtidas nas entrevistas, de ambas as turmas, residia na questão de como muitos desses alunos reconheciam que não reservavam um tempo específico para um estudo complementar da matéria estudada em sala de aula. O fator tempo, conforme foi observado, revelava-se delicado e preponderante ao aprendizado deste aluno. Torna-se comum muitos deles apenas reservar o tempo de se deslocar do mundo laboral que os cerca até a realidade circunscrita da escola.

Sobre o uso de estratégias de aprendizagem durante os momentos proporcionados na aprendizagem em Língua Inglesa, Perraudeau (2009) comenta nisso que as estratégias em si não são conscientes, uma vez que a sua variabilidade cognitiva impede a garantia da conservação de uma estratégia estruturada, seja com o passar do tempo ou por uma categoria de tarefas. Sobre alguns casos em que a estratégia falha, Perraudeau (2009) comenta que os alunos ainda apresentam uma falha na estrutura lógica de seu pensamento perante aquela característica, ou mesmo porque os procedimentos utilizados para a apresentação dos conteúdos não haviam sido bem-planejados. Também, nos estudos apresentados por Oxford (2003) e Oxford \& Nyikos (1989), aprendizes de Língua Estrangeira que buscam por pensarem e cogitarem o uso de estratégias de variadas naturezas revelam-se como os melhores alunos. Quando apenas focavam-se na habilidade da escrita, isto acabava por 
apenas aprimorar partes de sua prática comunicativa e a parte da escrita, não garantindo o aprimoramento das demais habilidades.

Assim, os efeitos que as estratégias de aprendizagem trazem aos alunos devem ser bemavaliados, como Perraudeau (2009) sugere, uma vez que estes instrumentos “[...] estão longe de ser milagrosos e não substituem de modo algum as aprendizagens disciplinares” (p. 166). De tal forma, cabe ao professor decidir se tornar-se-ia válido ou não utilizar explanações e sugestões de estratégias de aprendizagem em sua turma. Perraudeau (2009) comenta que estas devem ser realizadas de forma prudente. Ele afirma que o professor deve ter uma ideia de como a estratégia funcionaria para aplicá-la junto ao aluno.

\section{CONSIDERAÇÕES FINAIS}

Este estudo buscou responder o seu objetivo, de evidenciar quais as estratégias utilizadas por alunos adultos na aprendizagem da Língua Inglesa e como elas ocorrem, dentro do contexto de uma sala de aula de uma escola de idiomas. Durante a análise inicial, percebeuse que boa parte dos sujeitos da pesquisa apoiam-se na escrita como uma estratégia de captar os elementos linguísticos a eles apresentados. Demais formas eram adotadas, para além da escrita, como o uso de recursos on-line e acessibilidade portátil em seus aparelhos celulares, permeavam entre as suas respostas. A preocupação em saber o significado da palavra correspondente à Língua Portuguesa era constante na fala dos alunos. Havia uma necessidade que eles apresentavam em seu aprendizado de saber cada pormenor da frase que lhes era apresentada.

A Língua Portuguesa era fortemente utilizada como apoio pelos alunos na elaboração e consolidação do vocabulário em Língua Inglesa. Para além da tradução, havia a necessidade de tomar a referência da fonética da Língua Materna como auxílio na pronúncia na LínguaAlvo estudada em sala de aula. Isso permitia que estes alunos conseguissem elaborar e falar de acordo com as regras gramaticais. Isto, no entanto, vinha a lhes atrapalhar em alguns momentos, uma vez que o sentido apresentado pelo inglês não é o mesmo percebido na Língua Portuguesa.

As dificuldades que estes alunos se deparavam eram justamente em torno da pronúncia, por esta não acompanhar o mesmo embasamento linguístico da Língua Materna. Por, às vezes, não ter havido uma correspondência destas perspectivas, acabavam criando barreiras entre si, fazendo com que o professor buscasse novas formas de auxiliar o aluno a 
quebrar este bloqueio em sua aprendizagem linguística. Via-se este uso, quase que extrapolado da Língua Portuguesa em sala de aula, como uma necessidade de suprimir os receios que se apresentavam em sua produção. Nisso se revela o grande desafio com que o aluno adulto se depara em seu processo de aprendizagem. As estratégias que utiliza em sala de aula, seja por meio da escrita, pela associação de imagens, ou, até mesmo, como alguns pontuaram, pelo desenho representativo de palavras surgidas na ponta da caneta, nada mais são do que meios que encontram para alcançar o seu principal objetivo: falar em inglês.

Por mais que houvesse uma prática diária, pontuada por revisão de anotações das aulas, ou por outras fontes da língua como seriados e filmes em inglês, muitos ainda dependiam do apoio e suporte do professor em sala de aula, ou mesmo reservam apenas um tempo dedicado ao estudo da Língua Inglesa dentro da realidade da sala de aula como aponta Gaugler (2016) em seus estudos. Outro fator que vinha a se revelar como obstáculo era o tempo que o aluno adulto possuía para seu estudo. A falta de uma organização e linearidade nos estudos que iam além da sala de aula revelavam-se como grandes empecilhos para que a sua aprendizagem e aquisição fosse efetiva. O aluno, portanto, necessita estar ciente de que, a partir do momento em que decide que irá iniciar estudos aprofundados em uma Segunda Língua, a organização e a administração de seu tempo devem ser totalmente avaliadas.

Deparou-se também neste cenário com a falta de segurança do aluno perante sua aprendizagem. Esta é resultante de variados fatores, desde experiências negativas do passado até questões internas dos alunos. Esta sombra de dúvidas e receios vem acompanhando-os no decorrer do trajeto. $\mathrm{O}$ aluno acaba descobrindo que essa trilha que segue nesta nova etapa de sua vida, revela-se curvilínea, com obstáculos surgindo na medida em que vai avançando em sua aprendizagem. Ele sabe, porém, que deve seguir. Um momento de hesitação pode significar um momento em que ele pondera se deve continuar no trajeto, ou rumar em outra direção. Neste sentido, o apoio oferecido por familiares e amigos revela-se de suma importância para que ele permaneça firme nesta nova empreitada linguística; não, no entanto, apenas o apoio destes sujeitos, mas a própria figura do professor revela-se de importante expressão em seu aprendizado.

O papel desempenhado pelo professor na aprendizagem do aluno portou-se como elemento significativo neste processo. O professor aqui deve se portar como mediador dos conhecimentos trazidos pelos alunos e pelos conhecimentos a serem administrados no contexto da aquisição linguística. A forma também como o professor reage as ações dos alunos, como se relaciona com estes também auxilia para a sua permanência e não desistência dos estudos da língua. 
Neste sentido, o professor transmite a sensação de que a atividade trabalhada em sala de aula tenha um sentido na vivência dos alunos. Nas observações realizadas, as atividades aplicadas em sala de aula eram relacionadas a partir dos objetivos construídos e encontrados no Teacher's Book, cabendo ao professor decidir ou não as aplicar de acordo com a necessidade com que se deparava. Estas atividades atreladas ao mesmo objetivo comunicativo fazem parte de um conjunto maior dentro do contexto da aprendizagem da Língua Inglesa. Os alunos deveriam, portanto, perceber estas atividades como partes importantes a serem alcançadas no aprendizado.

Quanto ao uso de estratégias de aprendizagem dentro do contexto da sala de aula, elas devem condizer com a situação real da aprendizagem que se encontra no momento, e devem ter um significado para os alunos. Uma estratégia, entretanto, pode vir a funcionar para um aluno, enquanto para outro não. Por conta de seu caráter falível, ela não irá garantir a eficácia de uma aprendizagem, uma vez que estaria também sujeita às mudanças internas dos alunos. Dessa maneira, os efeitos de uma estratégia de aprendizagem adotada por um aluno, devem ser bem-avaliados. Cabe a este aluno, portanto, decidir se aquela determinada estratégia será útil ou não ao seu aprendizado.

O aprendizado não ocorre somente com a presença de um livro didático ou com recursos audiovisuais, mas, sim, com uma fonte de estímulo ao aprendizado do aluno. $\mathrm{O}$ aprendizado é mais do que isso; é um conjunto de iniciativas que o aluno toma para si procurando encontrar uma maneira mais apropriada para atingir o seu objetivo. Assim, o aprendizado da Língua Inglesa é possível. Por mais que adultos não consigam expressar, em um momento inicial, toda uma complexidade do pensamento dentro dos parâmetros linguísticos almejados, eles possuem ainda a capacidade de contornar estas dificuldades por si só, tendo o apoio do professor e dos demais envolvidos, e, principalmente, por conta deles, os principais agentes de sua aprendizagem.

Finalmente, seria uma boa ideia, os professores de segunda língua, considerar a reflexão de VanPatten (2017) sobre o fato de que o ensino de línguas precisa de uma pedagogia própria. As línguas não são aprendidas da mesma maneira que aprendemos outros componentes curriculares, como matemática, química ou história. O presente estudo mostrou que os alunos adultos fazem uso de diversas estratégias para compreender e transmitir suas mensagens na sala de aula de língua inglesa. Pesquisas futuras na área irão aprimorar nossa compreensão da complexidade envolvida no ensino e aprendizagem de uma segunda língua e a participação dos professores nesse processo. 


\section{REFERÊNCIAS BIBLIOGRÁFICAS}

BALLMAN, T. L.; LISKIN-GASPARRO, J. E.; MANDELL, P. B. (2001). The Case for Classroom Communication. In: T.L. BALLMAN; J.E. LISKIN-GASPARRO; P.B. MANDELL. AATSP Volume III The Communicative Classroom: AATSP Professional Development Series Handbook for Teachers K-16. Boston, Estados Unidos: Heinle \& Heinle, p. 1-30.

DEAQUINO, C. T. E. (2007). Como aprender: andragogia e as habilidades de aprendizagem. $1^{a}$ ed. São Paulo: Pearson Prentice Hall, 142 p.

DEMANDAS de Aprendizagem de Inglês no Brasil. 2013. Disponível em: <https://www.britishcouncil.org.br/sites/default/files/demandas_de_aprendizagempesqu isacompleta.pdf $>$. Acesso em: 28/10/2015.

Ellis, R., Skehan, P., Li, S., Shintani, N., \& Lambert, C. (2019). Pedagogical Perspectives. In: Task-Based Language Teaching: Theory and Practice (Cambridge Applied Linguistics, pp. 175-280). Cambridge: Cambridge University Press. doi:10.1017/9781108643689.011

Gaugler, K. (2016). Technology and the 21st century language classroom. In: Teacher's Handbook: Contextualized Language Instruction, 5th ed. Boston: Heinle \& Heinle.

Lee, J.; VanPatten, B. (2003). Making Communicative Language Teaching Happen. (2nd Ed.). New York: McGraw-Hill

LEMOV, D. (2011). Aula Nota 10: 49 técnicas para ser um professor campeão de audiência. $1^{\mathrm{a}}$ ed. Tradução Leda Beck. Consultoria e revisão técnica Guiomar Namo de Mello e Paula Louzano. São Paulo: Da Boa Prosa; Fundação Lemann, 330 p.

Lightbown, P.; Spada, N. (2013). How languages are learned (4th ed.). Oxford University Press.

MEIRIEU, P. (1998). Aprender... sim, mas como. $7^{\text {a }}$ ed. Tradução Vanise Dresch. Porto Alegre: Artes Médicas, 193 p.

OXFORD, R. L. (1990). Language Learning Strategies: What Every Teacher Should Know. $2^{a}$ ed. Boston, MA: Heinle \& Heinle Publishers, 343 p.

(2003). Language learning styles and strategies: an overview. GALA, p. 1-25.

OXFORD, R.; NYIKOS, M. (1989). Variables affecting choice of language learning strategies by university students. In: The Modern Language Journal, Columbus, Ohio: 73, iii, p. 291-300.

PERRAUDEAU, M. (2009). Estratégias de aprendizagem: como acompanhar os alunos na aquisição dos saberes. Tradução Sandra Loguercio. Porto Alegre: Artmed, 228 p. 
Shrum, J.; Glisan, E. (2016). Teacher's Handbook: Contextualized Language Instruction, 5th ed. Boston: Heinle \& Heinle.

Spicer-Escalante (2019). El Método Comunicativo y la Preparación de Maestros de Segunda Lengua para Satisfacer las Demandas Globales. En: Investigación en Lenguas, Educación y Literatura, Marisa Trejo Sirvent (Coord.). Tuxtla Gutiérrez, Chiapas: Historia Herencia Mexicana: 137-148. SBN 978-607-561-015-3

VanPatten, B. (2017). While we're on the topic on language acquisition and classroom practice. Alexandria, VA: ACTFL Publications 